\title{
Dietary supplementation with chitosan oligosaccharide affects serum lipids and nutrient digestibility in broilers
}

\author{
T. Tufan ${ }^{1} \&$ C. Arslan² \\ ${ }^{1}$ Department of Animal Nutrition and Nutritional Disease, Faculty of Veterinary Medicine, Siirt University, Siirt, Turkey. \\ ${ }^{2}$ Department of Animal Nutrition and Nutritional Disease, Faculty of Veterinary Medicine, Selçuk University, Konya, \\ Turkey
}

(Submitted 5 April 2018; Accepted 5 January 2020; Published 9 October 2020)

Copyright resides with the authors in terms of the Creative Commons Attribution 4.0 South African Licence.
See: http://creativecommons.org/licenses/by/4.0/za
Condition of use: The user may copy, distribute, transmit and adapt the work, but must recognise the authors and the South African
Journal of Animal Science.

\begin{abstract}
This research was conducted to determine the effects of supplementation of chitosan oligosaccharide (COS) on the growth performance, blood parameters, carcass traits, fatty acid composition of breast meat, and apparent nutrient digestibility in broiler chickens. A total of 375 one-day-old Ross 308 male chicks were allocated to a control diet (T1) or diets supplemented with $50 \mathrm{ppm}$ (T2) and $100 \mathrm{ppm}$ (T3) of COS. There were five replicates of 25 chicks for each treatment. All the experimental birds were fed a starter (days $1-4$ ), grower (days 15 - 28), and finisher diet (days 29 - 42). No differences were detected among treatments for live weight, gain, feed intake or feed conversion, except that feed intake was depressed in T3 during the grower period. Serum total protein and albumin levels did not differ among the treatments. Serum total cholesterol, low density lipoproteins (LDL), very low density lipoproteins (VLDL) and triglyceride concentrations were reduced significantly by supplementation with COS, whereas the high density lipoprotein $(\mathrm{HDL})$ concentration was significantly lower only for T2 relative to $T 1$. The dressing percentage was significantly higher for T2 and T3 than for T1. Fatty acid composition of the breast meat was unaffected by the treatments. The digestibility of the diet and some of its constituents was affected in a graduated manner by the addition of COS. Thus, supplementation of broiler diets with COS improved carcass yield and had a hypolipidemic effect in improving the serum lipid profile.
\end{abstract}

Keywords: carcass, digestibility, hypolipidemic effect, performance

${ }^{\#}$ Corresponding author: tuncay-tufan@hotmail.com

\section{Introduction}

Since 1 January 2006, antibiotics have been prohibited as feed additives in the European Union and other countries, including Turkey. This prohibition has prompted further studies on alternative feed additives with similar effects. Prebiotics are defined as an undigested dietary supplement that promotes growth and acts as an antibiotic alternative that affects the health status of the supplemented individual favourably (Gibson \& Roberfroid, 1995; Tufan et al., 2015). Various oligosaccharides are accepted as prebiotics. One of these compounds is chitosan oligosaccharide (COS), which is the second most common carbohydrate polymer in nature after cellulose. Chitosan oligosaccharide is obtained from chitin by chemical and enzymatic hydrolysis of polychitosan and has low molecular weight compared with chitin and chitosan. Its viscosity is also low, and it can be dissolved easily in water (Xiaofeng et al., 2017). Chitosan oligosaccharide is antimicrobial, antidiabetic, antitumoral, antifungal, antioxidant, and hypocholesterolemic.

Some studies examined the use of COS as a feed additive for poultry (e.g. Gao, et al., 2001; Lee et al., 2002; Huang et al., 2007; Wang, 2008; Tufan et al., 2015). It enhances the immune function and scavenges free radicals when used as a supplement for broilers (Huang et al., 2005; Kim \& Rajapakse, 2005; Huang et al., 2007; Tufan et al., 2015; Xiaofeng et al., 2017). There have been reports that dietary supplementation with COS might increase blood serum high-density lipoprotein (HDL) cholesterol and decrease the abdominal fat content, thus improving the quality of meat from broiler chickens (Wang et al., 1998; Tang et al., 2005; Zhou et al., 2009). Li et al. (2007) reported that dietary supplementation with COS increased nutrient digestibility in broiler chickens. 
To date, there have been variable outcomes from studies that examined the effects of dietary supplementation on growth performance of broiler chickens. Zhou et al. (2009) and Wang et al. (2003) reported that COS supplementation had a positive effect on growth performance. However, other studies failed to detect this favourable effect (Razdan \& Petterson, 1994; Kobayashi et al., 2006a; Keser et al., 2011). Therefore, this study was conducted to determine the effects of chitosan oligosaccharide supplementation on growth, serum protein and lipid fractions, carcass yield, breast meat fatty acid profile, and nutrient digestibility in broiler chickens.

\section{Material and Methods}

This research was approved by the Ethics Committee of the Faculty of Veterinary Medicine, Kafkas University, 2010-35. Three hundred and seventy-five one-day old male broiler chicks (Ross 308) were randomly allotted to a control diet (T1) or diets supplemented with 50 ppm (T2) and 100 ppm (T3) COS (GlycoBio Co., Dalian, China). There were five replicates of 25 chicks for each treatment. The study was conducted in three feeding periods, namely a starter period for the first 14 days, a grower period from day 15 to day 28 , and a finisher period from day 29 to day 42 . The chicks were fed corn and soybean-based diets that were formulated according to NRC (1994) recommendations (Table 1). The dry matter, deacetylation degree and molecule weight of the COS, as declared by the supplier, were $5.0-6.5,90^{+} \%, 85^{+} \%$, and $\leq 1000$ Da, respectively. The chicks had ad libitum access to feed and water.

The chicks were housed on wood shavings in an automatically ventilated room. For the first three days, the temperature of the room was maintained at $33 \pm 1{ }^{\circ} \mathrm{C}$. Then the temperature was gradually decreased until the last two weeks of the study, when it was kept at $22 \pm 1^{\circ} \mathrm{C}$. During the first three days of the study, light was provided for 23 hours a day, and then the lighting schedule allowed for 16 hours of light and 8 hours of darkness each day. Light intensity was approximately 20 lux at bird level throughout the experimental period. The chicks were vaccinated against Newcastle disease and infectious bronchitis at hatching and on day 14, and against infectious bursal disease on day 15 . The birds were monitored daily for wellbeing and mortality.

The chicks were weighed biweekly. The average daily weight gain was calculated by dividing the difference between the final weight and the initial weight by fourteen. Feed intake was also determined biweekly by deducting the remaining feed from the total feed given during the fourteen-day period. Daily average feed consumption was calculated by dividing average daily feed intake by the total number of birds in the replicate. Feed conversion ratio was calculated by dividing the average daily feed consumption by average daily weight gain.

At the end of the experiment (day 42), five birds from each replicate were randomly selected and a blood sample was drawn from their Vena subcutenea ulnaris (25 blood samples per treatment). The samples were centrifuged at $3000 \mathrm{~g}$ for 10 minutes, and the serum was stored at $-20^{\circ} \mathrm{C}$ for subsequent analyses. Five birds were randomly chosen from each replicate and slaughtered to determine the carcass yield and the weights of the internal organs. The carcasses were cut into parts according to Jones (1984). Samples of the breast meat were taken from the middle third of the muscle on both sides of the birds. They were kept at -20 ${ }^{\circ} \mathrm{C}$ until analysed for their fatty acid contents.

On days 39 and 40, excreta samples were collected from each replicate, mixed to homogenize, placed in a plastic container, and kept frozen at $-20^{\circ} \mathrm{C}$ until they were analysed. All chemical analyses of the diets and excreta used AOAC (2000) recommended procedures. For the nutrient analyses, the excreta samples were thawed at room temperature. Crude protein content was determined using the wet excreta. The remaining excreta samples were dried at $65^{\circ} \mathrm{C}$ in a forced-air oven and crushed with a porcelain mortar and pestle to a dust-like consistency. Nutrient digestibility was estimated using acid insoluble ash (AIA) as an indigestible marker (Ergün et al., 2017). Thus,

$$
\text { digestibility }=100-\frac{\text { AIA in feed } x \text { Nutrient in excreta }}{\text { AIA in excreta } x \text { Nutrient in feed }} \times 100
$$

The total protein, albumin, total cholesterol, HDL, low-density lipoprotein (LDL), and triglyceride contents of the serum samples were determined with a HumaStar 600 autoanalyser (HUMAN Gesellschaft für Biochemica und Diagnostica $\mathrm{mbH}$, Wiesbaden, Germany). The amount of very low density lipoprotein (VLDL) was calculated according to Edwards et al. (1999). 
Table 1 Composition and nutrient content of basal diets fed to broilers during the starter, grower and finisher phases of the study

\begin{tabular}{|c|c|c|c|}
\hline Ingredient, \% & Starter phase & Grower phase & Finisher phase \\
\hline Wheat & 20.13 & 29.95 & 39.73 \\
\hline Yellow corn & 27.03 & 19.60 & 10.21 \\
\hline Soybean meal, $44 \% \mathrm{CP}$ & 23.94 & 17.73 & 14.24 \\
\hline Full fat soybean & 15.00 & 15.00 & 20.00 \\
\hline Poultry meal & 4.00 & 5.00 & 5.00 \\
\hline Vegetable oil & 3.10 & 5.04 & 6.00 \\
\hline Sunflower meal, $28 \%$ CP & 1.67 & 2.56 & - \\
\hline Meat-bone meal & 2.00 & 2.00 & 2.00 \\
\hline Limestone & 0.62 & 0.66 & 0.68 \\
\hline Dicalcium phosphate & 0.62 & 0.47 & 0.45 \\
\hline Salt & 0.30 & 0.30 & 0.30 \\
\hline Vitamin/mineral premix ${ }^{1}$ & 0.30 & 0.30 & 0.25 \\
\hline DL-methionine & 0.40 & 0.36 & 0.37 \\
\hline L-lysine & 0.21 & 0.32 & 0.26 \\
\hline Sodium bicarbonate & 0.30 & 0.32 & 0.31 \\
\hline Choline chloride & 0.10 & 0.10 & - \\
\hline Mycobond & 0.10 & 0.10 & 0.10 \\
\hline Salgard & 0.10 & 0.10 & - \\
\hline Roviyo enzyme & 0.10 & 0.10 & 0.10 \\
\hline \multicolumn{4}{|l|}{ Analysed nutritive value } \\
\hline $\mathrm{ME}, \mathrm{kcal} / \mathrm{kg}^{5}$ & 3010 & 3111 & 3200 \\
\hline Dry matter, \% & 93.20 & 93.47 & 93.67 \\
\hline Crude protein, $\%$ & 24.10 & 21.90 & 20.08 \\
\hline Ether extract, \% & 10.94 & 13.67 & 13.59 \\
\hline Crude fibre, \% & 4.99 & 3.66 & 5.94 \\
\hline Crude ash, \% & 5.41 & 6.09 & 6.68 \\
\hline Estimated calcium content, \% & 1.00 & 0.90 & 0.90 \\
\hline Estimated phosphorus content, \% & 0.78 & 0.76 & 0.75 \\
\hline
\end{tabular}

${ }^{1}$ Vitamin $A: 6.35 \mathrm{mg}$, vitamin $\mathrm{D}_{3}: 3.39 \mathrm{mg}$, vitamin $\mathrm{E}: 40 \mathrm{mg}$, vitamin $\mathrm{K}_{3}: 1.6 \mathrm{mg}$, vitamin $\mathrm{B}_{1}: 12 \mathrm{mg}$, vitamin $\mathrm{B}_{2}: 32 \mathrm{mg}$, niacin: $24 \mathrm{mg}$, calcium D-Pantothenate: $72 \mathrm{mg}$, vitamin $B_{6}: 20 \mathrm{mg}$, vitamin $B_{12}: 64 \mathrm{mg}$, D-Biotin: $80 \mathrm{mg}$, folic acid: $8 \mathrm{mg}$, vitamin C: $400 \mathrm{mg}$, manganese: $42 \mathrm{mg}$, iron: $33.6 \mathrm{mg}$, zinc: $33.6 \mathrm{mg}$, copper: $3.6 \mathrm{mg}$, cobalt: $0.80 \mathrm{mg}$, iodine: $0.40 \mathrm{mg}$, selenium: $0.72 \mathrm{mg}$, molybdenum: $0.41 \mathrm{mg}$.

Mycobond: sodium aluminosilicate; Salgard: propionic acid $170000 \mathrm{ml}$, ammonium propionate $80000 \mathrm{ml}$; ammonium formate $170000 \mathrm{ml}$, formic acid $330000 \mathrm{ml}$; Roviyo enzyme: Wheatzyme 80000 mg, phytase $20000 \mathrm{mg}$

Concentrations of individual fatty acids of breast meat were analysed with a gas chromatograph (Agilent Technologies, Santa Clara, California, USA) equipped with an auto sampler following the methods described by Paquot (2013). Chromatographic separations were accomplished with an Optima delta-6 capillary column $(0.25 \mathrm{~mm}$ i.d. $\times 60 \mathrm{~m}$, film thickness $0.25 \mu \mathrm{m})$. Analysis was carried out with nitrogen as the carrier gas. The column temperature ranged from an initial temperature of $50{ }^{\circ} \mathrm{C}$, held for 1 minute, then ramped from $50{ }^{\circ} \mathrm{C}$ to $300{ }^{\circ} \mathrm{C}$ at $3{ }^{\circ} \mathrm{C}$ per minute, and held for 5 minutes. The detector temperature was 250 ${ }^{\circ} \mathrm{C}$. The separated components were identified by retention time of matching standard fatty acid methyl esters. The external standard method was used. Quantitative determination was carried out based on peak area integration. 
Data were analysed by one-way ANOVA with SPSS 16.0 (SPSS Inc., Chicago, Illinois, USA). Duncan's multiple comparison test was used to compare the treatment means $(P<0.05)$. The results are presented as mean \pm standard error.

\section{Results and Discussion}

Mortality rates in $\mathrm{T} 1, \mathrm{~T} 2$, and $\mathrm{T} 3$ were $11.2 \%, 4.8 \%$ and $8.8 \%$, respectively. The Chi square value testing independence of treatments and mortality was $3.44(P>0.10)$.

No differences were detected among the treatments for live weight, average live weight gain, average feed intake and feed conversion ratio during the starter, grower and finisher periods, except that feed intake was depressed in T3 during the grower period. In aggregate, no significant differences were detected among treatments for the entirety of the study (Table 2).

Table 2 Effects of chitosan oligosaccharide supplementation of diets on growth performance of broiler chickens

\begin{tabular}{|c|c|c|c|c|}
\hline \multirow{2}{*}{ Parameters } & \multicolumn{3}{|c|}{ Treatments } & \multirow{2}{*}{$P$-value } \\
\hline & Control diet & 50 ppm COS & 100 ppm COS & \\
\hline Initial weight, g & $37.06 \pm 0.04$ & $37.02 \pm 0.05$ & $37.02 \pm 0.05$ & 0.783 \\
\hline \multicolumn{5}{|l|}{ Starter period (days 0 - 14) } \\
\hline Live weight, $g$ & $383.26 \pm 7.90$ & $387.00 \pm 4.69$ & $391.04 \pm 12.04$ & 0.823 \\
\hline Average live weight gain, $\mathrm{g} / \mathrm{d}$ & $24.73 \pm 1.24$ & $25.00 \pm 0.73$ & $25.29 \pm 1.93$ & 0.825 \\
\hline Average feed intake, $\mathrm{g} / \mathrm{d}$ & $27.64 \pm 0.66$ & $27.68 \pm 0.46$ & $27.90 \pm 0.36$ & 0.875 \\
\hline Feed conversion & $1.12 \pm 0.03$ & $1.11 \pm 0.02$ & $1.10 \pm 0.02$ & 0.344 \\
\hline \multicolumn{5}{|l|}{ Grower period (days 15 - 28) } \\
\hline Live weight, $\mathrm{g}$ & $1403.16 \pm 20.40$ & $1435.58 \pm 17.24$ & $1397.04 \pm 31.42$ & 0.490 \\
\hline Average live weight gain, $\mathrm{g} / \mathrm{d}$ & $72.85 \pm 2.26$ & $74.90 \pm 1.36$ & $71.86 \pm 3.49$ & 0.224 \\
\hline Average feed intake, $\mathrm{g} / \mathrm{d}$ & $108.58 \pm 3.65^{\mathrm{a}}$ & $106.66 \pm 4.66^{\mathrm{ab}}$ & $101.40 \pm 2.98^{b}$ & 0.031 \\
\hline Feed conversion & $1.49 \pm 0.04$ & $1.43 \pm 0.05$ & $1.41 \pm 0.04$ & 0.208 \\
\hline \multicolumn{5}{|l|}{ Finisher period (days 29 - 42) } \\
\hline Live weight, $\mathrm{g}$ & $2666.04 \pm 27.41$ & $2804.82 \pm 30.41$ & $2718.14 \pm 68.19$ & 0.140 \\
\hline Average live weight gain, $\mathrm{g} / \mathrm{d}$ & $90.20 \pm 5.72$ & $97.80 \pm 5.61$ & $94.36 \pm 6.51$ & 0.173 \\
\hline Average feed intake, $\mathrm{g} / \mathrm{d}$ & $181.64 \pm 3.27$ & $189.38 \pm 5.96$ & $187.64 \pm 9.33$ & 0.195 \\
\hline Feed conversion & $2.03 \pm 0.14$ & $2.01 \pm 0.06$ & $2.06 \pm 0.04$ & 0.652 \\
\hline \multicolumn{5}{|l|}{ Overall (days 1 - 42) } \\
\hline Average live weight gain, $\mathrm{g} / \mathrm{d}$ & $62.59 \pm 1.43$ & $65.90 \pm 1.63$ & $63.84 \pm 3.64$ & 0.140 \\
\hline Average feed intake, $\mathrm{g} / \mathrm{d}$ & $105.94 \pm 0.68$ & $107.90 \pm 0.82$ & $105.66 \pm 3.26$ & 0.223 \\
\hline Average feed conversion & $1.55 \pm 0.04$ & $1.52 \pm 0.01$ & $1.52 \pm 0.02$ & 0.234 \\
\hline
\end{tabular}

Serum total protein and albumin concentrations were not different among the groups (Table 3). Total cholesterol, LDL, VLDL, and triglyceride concentrations were lower in T2 and T3 than the control group. The $\mathrm{HDL}$ concentration was lower in T2 than the control $(P<0.05)$. 
Table 3 Effects of chitosan oligosaccharide supplementation of diets for broiler chicken on certain serum constituents

\begin{tabular}{lrrrr}
\hline \multirow{2}{*}{ Serum constituents } & \multicolumn{3}{c}{ Treatments } & $P$-value \\
\cline { 2 - 4 } & \multicolumn{1}{c}{ Control diet } & 50 ppm COS & 100 ppm COS & \\
\hline Total protein, g/dL & $3.42 \pm 0.23$ & $3.20 \pm 0.31$ & $2.69 \pm 0.19$ & 0.107 \\
Albumin, g/dL & $0.71 \pm 0.06$ & $0.56 \pm 0.05$ & $0.61 \pm 0.04$ & 0.106 \\
Total cholesterol, mg/dL & $68.47 \pm 3.50^{\mathrm{a}}$ & $53.20 \pm 4.06^{\mathrm{b}}$ & $53.90 \pm 2.48^{\mathrm{b}}$ & 0.003 \\
HDL, mg/dL & $41.18 \pm 2.06^{\mathrm{a}}$ & $34.80 \pm 2.22^{\mathrm{b}}$ & $35.69 \pm 1.57^{\mathrm{ab}}$ & 0.052 \\
LDL, mg/dL & $20.36 \pm 1.60^{\mathrm{a}}$ & $12.92 \pm 1.85^{\mathrm{b}}$ & $12.34 \pm 0.92^{\mathrm{b}}$ & 0.001 \\
VLDL, mg/dL & $6.94 \pm 0.42^{\mathrm{a}}$ & $5.51 \pm 0.42^{\mathrm{b}}$ & $5.86 \pm 0.21^{\mathrm{b}}$ & 0.019 \\
Triglycerides, mg/dL & $34.68 \pm 2.08^{\mathrm{a}}$ & $27.56 \pm 2.11^{\mathrm{b}}$ & $29.28 \pm 1.07^{\mathrm{b}}$ & 0.020
\end{tabular}

\footnotetext{
${ }^{a, b}$ Within a row, mean values with a common superscript did not differ at $P=0.05$

COS: chitosan oligosaccharide; HDL: high density lipoprotein, LDL: low density lipoprotein, VLDL: very low density lipoprotein
}

Live weight at slaughter and the weights of abdominal fat, heart, spleen, and gizzard of the chicks did not differ among treatments (Table 4). The dressing percentages of the birds and their wing weight differed among the treatments $(P<0.05$ and $P<0.001$, respectively) with T2 and T3 being greater than T1. Breast weights of the birds that were received the intermediate level of COS were higher than those of either T1 or T3 $(P<0.01)$. Leg weights of the birds in T2 exceeded those of T1 $(P<0.01)$ but were not significantly different from T3. The liver weights of the birds at slaughter decreased in a graduated manner with T3 being significantly less than T1 $(P<0.05)$.

Table 4 Effects of chitosan oligosaccharide supplementation of diets fed to broiler chickens on carcass traits

\begin{tabular}{|c|c|c|c|c|}
\hline \multirow{2}{*}{ Traits } & \multicolumn{3}{|c|}{ Treatments } & \multirow{2}{*}{$P$-value } \\
\hline & Control diet & 50 ppm COS & 100 ppm COS & \\
\hline Slaughter live weight, g & $2654.10 \pm 38.37$ & $2756.16 \pm 34.83$ & $2683.88 \pm 36.48$ & 0.135 \\
\hline Dressing percentage & $70.24 \pm 0.69^{b}$ & $73.05 \pm 0.94^{\mathrm{a}}$ & $72.48 \pm 0.50^{a}$ & 0.021 \\
\hline Breast weight, $\mathrm{g}$ & $634.46 \pm 12.68^{b}$ & $689.25 \pm 12.00^{\mathrm{a}}$ & $652.83 \pm 13.00^{b}$ & 0.010 \\
\hline Leg weight, g & $775.02 \pm 14.19^{b}$ & $842.62 \pm 12.61^{a}$ & $810.15 \pm 13.87^{a b}$ & 0.003 \\
\hline Wing weight, $g$ & $210.27 \pm 4.91^{b}$ & $235.96 \pm 4.07^{\mathrm{a}}$ & $238.96 \pm 3.47^{\mathrm{a}}$ & 0.000 \\
\hline Abdominal fat weight, $g$ & $18.97 \pm 1.85$ & $16.07 \pm 1.02$ & $18.48 \pm 1.81$ & 0.398 \\
\hline Heart weight, $g$ & $14.54 \pm 0.51$ & $13.51 \pm 0.44$ & $14.40 \pm 0.56$ & 0.302 \\
\hline Liver weight, $g$ & $67.57 \pm 2.67^{\mathrm{a}}$ & $61.92 \pm 1.94^{\mathrm{ab}}$ & $60.17 \pm 1.42^{b}$ & 0.036 \\
\hline Spleen weight, g & $3.24 \pm 0.18$ & $3.23 \pm 0.20$ & $3.24 \pm 0.14$ & 0.998 \\
\hline Gizzard weight, g & $41.08 \pm 2.12$ & $38.67 \pm 1.13$ & $38.07 \pm 1.34$ & 0.369 \\
\hline
\end{tabular}

\footnotetext{
${ }^{a, b}$ Within a row, mean values with a common superscript did not differ at $P=0.05$ COS: chitosan oligosaccharide
}

No significant differences were detected among treatments in the individual fatty acid content, total saturated fatty acids (SFA), total monounsaturated fatty acids (MUFA) and total polyunsaturated fatty acids (PUFA) contents of breast (Table 5). 
Table 5 Effects of chitosan oligosaccharide supplementation of diets on fatty acid composition of breast meat from broilers

\begin{tabular}{|c|c|c|c|c|}
\hline \multirow{2}{*}{ Fatty acids, \% } & \multicolumn{3}{|c|}{ Treatments } & \multirow{2}{*}{$P$-value } \\
\hline & Control diet & 50 ppm COS & 100 ppm COS & \\
\hline Myristic acid & $0.31 \pm 0.01$ & $0.33 \pm 0.01$ & $0.32 \pm 0.01$ & 0.196 \\
\hline Pentadecylic acid & $0.09 \pm 0.00$ & $0.08 \pm 0.01$ & $0.10 \pm 0.00$ & 0.009 \\
\hline Palmitic acid & $14.15 \pm 0.18$ & $14.61 \pm 0.23$ & $14.50 \pm 0.16$ & 0.230 \\
\hline Margaric acid & $0.20 \pm 0.01$ & $0.21 \pm 0.01$ & $0.22 \pm 0.05$ & 0.382 \\
\hline Stearic acid & $5.35 \pm 0.09$ & $5.39 \pm 0.12$ & $5.35 \pm 0.11$ & 0.942 \\
\hline Arachidic acid & $0.03 \pm 0.00$ & $0.04 \pm 0.00$ & $0.03 \pm 0.00$ & 0.208 \\
\hline Heneicosylic acid & $0.31 \pm 0.01$ & $0.30 \pm 0.01$ & $0.30 \pm 0.01$ & 0.705 \\
\hline Lignoceric acid & $0.05 \pm 0.01$ & $0.02 \pm 0.01$ & $0.03 \pm 0.09$ & 0.180 \\
\hline Palmitoleic acid & $1.44 \pm 0.11$ & $1.44 \pm 0.09$ & $1.53 \pm 0.10$ & 0.765 \\
\hline Oleic acid & $28.31 \pm 0.36$ & $28.63 \pm 0.34$ & $28.79 \pm 0.35$ & 0.609 \\
\hline Eicosenoic acid & $0.22 \pm 0.00$ & $0.23 \pm 0.00$ & $0.22 \pm 0.00$ & 0.282 \\
\hline Gadoleic acid & $0.60 \pm 0.03$ & $0.54 \pm 0.03$ & $0.55 \pm 0.02$ & 0.260 \\
\hline Nervonic acid & $0.17 \pm 0.01$ & $0.17 \pm 0.02$ & $0.17 \pm 0.01$ & 0.962 \\
\hline Linoleic acid & $41.57 \pm 0.49$ & $40.98 \pm 0.55$ & $40.89 \pm 0.46$ & 0.577 \\
\hline Eicosadienoic acid & $0.22 \pm 0.01$ & $0.21 \pm 0.01$ & $0.21 \pm 0.01$ & 0.582 \\
\hline Y-linolenic acid & $4.68 \pm 0.08$ & $4.61 \pm 0.07$ & $4.53 \pm 0.04$ & 0.285 \\
\hline a-linolenic acid & $0.06 \pm 0.01$ & $0.05 \pm 0.01$ & $0.06 \pm 0.01$ & 0.202 \\
\hline Cervonic acid & $0.05 \pm 0.01$ & $0.04 \pm 0.02$ & $0.01 \pm 0.01$ & 0.130 \\
\hline$\Sigma$ SFA & $20.48 \pm 0.21$ & $20.97 \pm 0.30$ & $20.83 \pm 0.20$ & 0.340 \\
\hline$\Sigma$ MUFA & $30.73 \pm 0.43$ & $31.01 \pm 0.41$ & $31.26 \pm 0.43$ & 0.681 \\
\hline$\Sigma$ PUFA & $46.58 \pm 0.56$ & $45.89 \pm 0.62$ & $45.70 \pm 0.49$ & 0.513 \\
\hline
\end{tabular}

COS: chitosan oligosaccharide

SFA: myristic acid, pentadecylic acid, palmitic acid, margaric acid, stearic acid, arachidic acid, heneicosylic acid, and lignoceric acid

MUFA: palmitoleic acid, oleic acid, eicosenoic acid, gadoleic acid, and nervonic acid

PUFA: linoleic acid, eicosadienoic acid, $y$-Linolenic acid, $\alpha$-Linolenic acid, and cervonic acid

Birds in T1 had greater digestibility of dry matter and crude fat than those in T3 $(P<0.05)$ (Table 6$)$. Organic matter digestibility was higher for birds in T1 than those in T2 and T3 $(P<0.05)$.

Table 6 Effects of chitosan oligosaccharide supplementation on the digestibility of dry matter, organic matter and crude fat in broiler chicks

\begin{tabular}{lcccc}
\hline \multirow{2}{*}{ Nutrient } & \multicolumn{3}{c}{ Treatments } & $P$-value \\
\cline { 2 - 3 } & Control diet & 50 ppm COS & 100 ppm COS & \\
\hline Dry matter & $96.15 \pm 0.24^{\mathrm{a}}$ & $95.52 \pm 0.12^{\mathrm{ab}}$ & $95.03 \pm 0.34^{\mathrm{b}}$ & 0.025 \\
Organic matter & $82.42 \pm 1.20^{\mathrm{a}}$ & $78.21 \pm 0.62^{\mathrm{b}}$ & $77.57 \pm 1.47^{\mathrm{b}}$ & 0.023 \\
Crude fat & $86.68 \pm 1.04$ & $83.79 \pm 0.43$ & $83.15 \pm 1.35$ & 0.066 \\
\hline
\end{tabular}

\footnotetext{
${ }^{\text {ab }}$ Within a row, mean values with a common superscript did not differ at $P=0.05$

COS: chitosan oligosaccharide
} 


\section{Discussion}

Supplementation of 50 and $100 \mathrm{ppm} \operatorname{COS}$ to the ration had no detectable effects on final live weight, average live weight gain, average feed intake and average feed conversion of broilers compared with unsupplemented birds over the 42-day feeding period. However, supplementation with COS produced numerical increases in the final live weights of the birds $(5.21 \%$ and $1.95 \%$ for T2 and T3, respectively). Such an increase could be economically profitable, if the effect were real. However, the current study lacked statistical power to detect effects of this magnitude. However, taken together with the results from other studies in which the addition of COS did not cause any difference to the live weight in broiler chickens (Huang et al., 2007; Keser et al., 2011), supplementation with COS cannot be advised based on the expectation of altered performance. In some studies, it was observed that chitosan has high viscosity and decreased feed intake and weight gain. Chitosan may have caused increased viscosity in the digestive system, which decreased the rate of passage of the digesta and the birds therefore consumed less feed (Razdan et al., 1996; Razdan \& Petterson, 1997). However, in this study, the lack of differences between treatments in feed intake might be associated with the low molecule weight and low viscosity of the COS that was used (Razdan \& Petterson, 1996; Razdan et al., 1997; Chae et al., 2005; Kim \& Rajapakse, 2005).

The results of this study also suggest that the addition of COS to broiler rations did not affect protein metabolism. Similar to this study, the addition of COS to broiler rations at various rates did not change serum concentrations of protein (Zhou et al., 2009; Keser et al., 2011) and albumin (Zhou et al., 2009). However, Li et al. (2007) found that adding COS to broiler rations at rates of 50 and $100 \mathrm{mg} / \mathrm{kg}$ increased serum protein levels significantly.

The results of the present study show that COS supplementation had a hypocholesterolemic effect in boiler chickens. Similar effects were reported (Razdan \& Petterson, 1994; 1996; Razdan et al., 1991; Osman et al., 2010). In contrast, adding chitosan to broiler rations did not alter serum HDL-cholesterol levels significantly (Keser et al., 2011; Razdan \& Petterson, 1994; Razdan \& Petterson, 1996; Razdan et al., 1997). Other researchers found that COS supplementation decreased serum triglyceride concentration significantly (Li et al., 2007; Zhou et al., 2009). The reasons for the decrease in serum lipid fractions may be associated with increased viscosity of the digesta in the intestine and a coincident decrease in lipid absorption (Razdan \& Petterson 1994; Razdan et al., 1997). Further evidence indicated decreased lipase activity in the small intestine (Kobayashi et al., 2002) and increased cholesterol in the faeces as a result of chitosan binding bile acids (Razdan \& Petterson 1996; Chiang et al., 2000; Zheng \& Zhu, 2003). There is a positive relationship between high serum triglyceride concentration and liver fat, and high serum triglyceride concentration may cause the condition commonly known as fatty liver. Low serum triglyceride content is thus desired for the continuity of the health of broiler chickens. In the current study, supplementing the broiler ration with 50 and $100 \mathrm{ppm}$ COS produced significant decreases in LDL, VLDL, and triglyceride concentrations. Similar to these results, it was observed that adding chitosan (Osman et al., 2010) and COS (Keser et al., 2011) to broiler rations reduced serum LDL concentration significantly. These decreases may be interpreted as indicating better health conditions for the broilers and for the people who eat them ultimately.

In this study, supplementation of the broiler diet with 50 and 100 ppm COS did not affect the weights of abdominal fat, hearth, spleen, and gizzard. Abdominal fat weight is an indicator of total body fat (Fortin et al., 1983; Sonarya, 1985) and less accumulation of abdominal fat is desired. Similar to the present results, Khambualai et al. (2008) found no difference in abdominal fat in broilers that were fed chitosan. However, there were several reports that supplementation of broiler rations with chitosan or COS decreased abdominal fat (Kobayashi et al., 2002; Kobayashi et al., 2006b; Zhou et al., 2009). Also similar to the present results, Zhou et al. (2009) found that chito-oligosaccharide supplementation did not affect spleen weight. Khambualai et al. (2008) found that chitosan supplementation did not affect heart weight in broilers. There were contradictory results of the effects of COS supplementation on the liver weight of broilers. Because liver weight in T3 was significantly lower than in T1, and T2 was intermediate, the present results suggest that the COS supplementation effect is dose dependent. However, Zhou et al. (2009) reported that adding COS to broiler rations increased the liver weight depending on the amount of COS. Wang et al. (2003) reported that supplementation of COS to broiler rations decreased the liver weight. Finally, there were reports of no differences in the liver weight of broilers as a function of COS supplementation (Kobayashi et al., 2006b; Kobayashi et al., 2006a; Khambualai et al., 2008).

Live weight at slaughter was unaffected by COS supplementation, but the dressing percentage was increased, leading to the expectation that one or more components of the carcass would be heavier in the supplemented birds. Increased wing weight was observed in both T2 and T3 relative to T1. In addition, T2 significantly increased breast weight compared with T1 and T3, and T2 significantly increased leg weight compared withT1. Taken together, these results might suggest an intermediate optimum level of COS supplementation. Zhou et al. (2009) reported that adding COS to rations did not have a significant effect on 
breast weight. Likewise, Khambualai et al. (2008) failed to detect a numerical increase in breast weight that resulted from chitosan supplementation.

In the current study, the effects of COS supplementation for broilers on the fatty acid profile of breast meat and on total SFA, MUFA, and PUFA concentrations were minimal. Unlike these results, Zhou et al. (2009) reported that adding COS to broiler rations decreased the SFA content and increased the MUFA and PUFA contents of the breast muscle.

Supplementation of the rations for broilers with COS decreased the digestibility of organic matter and dry matter in a dose-dependent manner. It also tended to decrease the digestibility of fat. The observed decreases in digestibility may be because of the increased viscosity of the digesta, slowing peristaltic movement of the intestines, binding fat micelle of the digesta, and suppressing enzymatic activity. Razdan and Petterson (1994) reported that chitosan increased the viscosity of the digesta, decreased the motility of the intestines, and inhibited the release of digestive enzymes, all affecting digestion negatively. However, Li et al. (2007) found that adding 50 or $100 \mathrm{ppm}$ COS to broiler rations did not affect dry matter digestion. Further, Lim et al. (2006) found that supplementation of broiler rations with $100 \mathrm{ppm}$ COS increased the digestibility of dry matter. This latter result was confirmed by Wang et al. (2008) with $0.05 \%, 0.10 \%$, and $0.15 \%$ COS supplementation of goose rations.

\section{Conclusion}

Supplementation of broiler rations with 50 and $100 \mathrm{ppm}$ COS had a favourable hypolipidemic effect on the birds without materially compromising their survival, performance, and serum fatty acid profile. Dressing percentage was also increased with modest effects on the weights of some carcass components. Digestibility of dietary dry matter, organic matter and crude fat may also be altered in a dose-dependent manner. Thus, COS might be useful as an alternative and natural feed additive in feeding broiler chickens.

\section{Acknowledgments}

This study was supported by Kafkas University Scientific Research Found, Project no: 2011- VF-36. The article is summarized from the PhD thesis of the first author. Some of these findings were presented at the $4^{t} h$ International Poultry Meat Congress in Antalya on 26-30 April 2017.

\section{Authors' Contributions}

TT and CA made equal contributions at every stage of this research.

\section{Conflict of Interest Declaration}

The authors declare no conflict of interest.

\section{References}

AOAC, 2000. Official methods of analysis of AOAC International. 17th edition. AOAC International, Maryland, USA, 2000.

Bolacali, M. \& Irak, K., 2017. Effect of dietary yeast autolysate on performance, slaughter, and carcass characteristics, as well as blood parameters, in quail of both genders. South African Journal of Animal Science 47, 460-470.

Chae, S.Y., Jang, M.K. \& Nah, J.W., 2005. Influence of molecular weight on oral absorption of water soluble chitosans. J. Control Release 102, 383-394.

Chiang, M.T., Yao, H.T. \& Chen, H.C., 2000. Effect of dietary chitosans with different viscosity on plasma lipids and lipid peroxidation in rats fed on a diet enriched with cholesterol. Biosci. Biotechn. Biochem. 64, 965-971.

Edwards, K., Kwaw, I., Matud, J. \& Kurtz, I., 1999. Effect of pistachio nuts on serum lipid levels in patients with moderate hypercholesterolemia. Journal of the American College of Nutrition 18, 229-232.

Ergün A., Çolpan I., Yıldız G., Küçükersan S., Tuncer ŞD., Yalçın S., Küçükersan MK., Şehu A. \& Saçaklı P., 2017. Hayvan Besleme ve Beslenme Hastalıkları. 7th edition. Pozitif Publications, Ankara.

Fortin, A., Grunder, A.A., Chambers, J.R. \& Hamılton, R.M.G., 1983. Live and carcass characteristics of four strains of male and female geese slaughtered at 173, 180 and 194 days of age. Poult. Sci. 62, 1217-1223.

Gao, F., Zhou, G.H. \& Han, Z.K., 2001. Effect of fructooligosaccharides (FOS) on growth performance, immune function and endocrine secretion in chicks. Acta Zool. Sinica. 13, 51-55.

Gibson, G.R. \& Roberfroid, M.B., 1995. Dietary modulation of the human colonic microbiota: Introducing the concept of prebiotics. J. Nutr. 125, 1401-1412, 1995.

Huang, R.L., Yin, Y.L., Wu, G.Y., Zhang, Y.G., Li, T.J., Li, L.L., Li, M.X., Tang, Z.R., Zhang, J., Wang, B., He, J.H. \& Nie, X.Z., 2005. Effect of dietary oligochitosan supplementation on ileal digestibility of nutrients and performance in broilers. Poult. Sci. 84, 1383-1388.

Huang, R.L., Deng, Z.Y., Yang, C.B., Yin, Y.L., Xie, M.Y., Wu, G.Y., Li, T.J., Li, L.L., Tang, Z.R., Kang, P., Hou, Z.P., Deng, D., Xiang, H., Kong, X.F. \& Guo, Y.M., 2007. Dietary oligochitosan supplementation enhances immune status of broilers. J. Sci. Food. Agric. 87(1), 53-159.

Jones, R. 1984. A standard method for the dissection of poultry for carcass analysis. West of Scotland Agricultural College, Auchincruive, Ayr. Technical note no 222. 
Keser, O., Bilal, T., Kutay, H.C., Abas, İ. \& Eseceli, H., 2011. Effects of chitosan oligosaccharide and/or beta-glucan supplementation to diets contained organic zinc on performance and some blood indices in broilers. Pak. Vet. J. 32, 15-19.

Khambualai, O., Yamauchi, K., Tangtaweewipat, S. \& İsarakul, B.C., 2008. Effects of dietary chitosan diets on growth performance in broiler chickens. J. Poult. Sci. 45, 206-209.

Khambualai, O., Yamauchi, K., Tangtaweewipat, S. \& İsarakul, B.C., 2009. Growth performance and intestinal histology in broiler chicken fed with dietary chitosan. Br. Poult. Sci. 50, 592-597.

Kim, S.K. \& Rajapakse, N., 2005. Enzymatic production and biological activities of chitosan oligosaccharides (COS): A review. Carbohydr. Polym. 62, 357-368.

Kobayashi, S., Terashima, Y. \& Itoh, H., 2006a. The effects of dietary chitosan or glucosamine $\mathrm{HCl}$ on liver lipid concentrations and fat depositions in broiler chickens. J. Poult. Sci. 43, 156-161.

Kobayashi, S., Terashima, Y. \& Itoh, H., 2006b. The effects of dietary chitosan on liver lipid concentrations in broiler chickens and treated with propylthiouracil. J. Poult. Sci. 43, 162-1636.

Kobayashi, S., Terashima, Y. \& Itoh, H., 2002. Effects of dietary chitosan on fat deposition and lipase activity in digesta in broiler chickens. Br. Poult. Sci. 43, 270-273

Lee, H.W., Park, Y.S., Jung, J.S. \& Shinin, W.S., 2002. Chitosan oligosaccharides, dp 2-8, have prebiotic effect on the Bifidobacterium bifidium and Lactobacillus sp. Anaerobe 8, 319-324.

Li, X.J., Piao, X.S., Kim, S.W., Liu, P., Wang, L., Shen, Y.B., Jung, S.C. \& Lee, H.S., 2007. Effects of chitooligosaccharide supplementation on performance, nutrient digestibility, and serum composition in broiler chickens. Poult. Sci. 86, 1107-1114.

NRC (National Research Council), 1994. Nutrient requirements of poultry. 9th revised edition. National Academy Press, Washington DC.

McLoughlin, R.F., Berthon, B.S., Jensen, M.E., Baines, K.J. \& Wood, L.G., 2017. Short-chain fatty acids, prebiotics, symbiotics, and systemic inflammation: A systematic review and meta-analysis. Am. J. Clin. Nutr. 106, 930-945.

Osman, M., Fayed, S.A., Ghada, I.M. \& Romeilah, R.M., 2010. Protective effects of chitosan, ascorbic acid and Gymnema sylvestre against hypercholesterolemia in male rats. Austr. J. Basic Appl. Sci. 4, 89-98.

Paquot, C., 2013. Standard methods for the analysis of oils, fats and derivatives. 6th edition. Elsevier Centre Nationale de la Recherche Scientifique, Thiais, France.

Razdan, A. \& Petterson, D., 1994. Effect of chitin and chitosan on nutrient digestibility and plasma lipid concentration in broiler chickens. Br. J. Nutr. 72, 277-288.

Razdan, A. \& Petterson, D., 1996. Hypolipidaemic, gastrointestinal and related responses of broiler chickens to chitosans of different viscosity. Br. J. Nutr. 76, 387-397.

Razdan, A., Petterson, D. \& Peterson, J., 1997. Broiler chicken body weights, feed intakes, plasma lipid and smallintestinal bile acid concentrations in response to feeding of chitosan and pectin. Br. J. Nutr. 78, 283-291.

Shi-bin, Y. \& Hong, C., 2012. Effects of dietary supplementation of chitosan on growth performance and immune index in ducks. Afr. J. Biotechnol. 11, 3490-3495.

Sonarya, E.B. 1985. Abdominal fat weight and thickness as predictors of total body fat in broilers. Br. Poult. Sci. 26, 453458.

Tang, Z.R., Yin, Y.L., Nyachoti, C.M., Huang, R.L., Li, T.J., Yang, C., Yang, X.J., Gong, J., Peng, J., Qi, D.S., Xing, J.J., Sun, Z.H. \& Fan, M.Z., 2005. Effect of dietary supplementation of chitosan and galacto-mannan-oligosaccharide on serum parameters and the insulin-like growth factor-I mRNA expression in early-weaned piglets. Domest. Anim. Endocrinol.28, 430-441.

Tufan, T., Arslan, C., Sari, M., Önk, K., Deprem, T. \& Celik, E., 2015. Effects of chitosan oligosaccharides addition to Japanese quail's diets on growth, carcass traits, liver and intestinal histology, and intestinal microflora. Kafkas Univ. Vet. Fak. Derg. 21, 665-671.

Wang, X.B., Wang, B.W., Zhang, L.Y., Duan, F. \& Li, C.E. 1998. Effects of chitosan supplementation on blood biochemistry indices and performance in broiler. China Feed 12, 19-21.

Wang, R.L., Chang, B. \& Du, B.W., 2008. Influence of chitosan on performance, nutrient utilization and blood biochemical parameters in goose. China Herbivores 02-2008.

Wang, X.W., Du, Y.G., Bai, X.F. \& Li, S.G., 2003. The effects of oligochitosan on broiler gut flora, microvilli density, immune function and growth performance. Acta Zoonutr. Sin. 15, 32-45.

Wang, X.W., Lin, X., Zhang, L., Du, Y.G., Bai, X.F. \& Shu, S.G., 2005. Effect of oligo-chitosan on broiler performance, small intestine structure and muscle mineral element concentration. J. China Cereals Oils Assoc. 20:83-88.

Xiaofeng, C.H.I., Xuemei, D.I.N.G., Xi, P.E.N.G., Xiaocong, L.I. \& Jing, F.A.N. G., 2017. Effects of chitosan oligosaccharides supplementation on the cell cycle of immune organs in broilers. Kafkas Univ. Vet. Fak. Derg., 23, $1003-1006$

Xiaocong, L.I., Xuemei, D.I.N.G., Xi, P.E.N.G., Xiaofeng, C.H. I., Hengmin, C.U.I., Zhicai, Z.U.O. \& Jing, F.A.N.G., 2017b. Effect of chitosan oligosaccharides on antioxidant function, lymphocyte cycle and apoptosis in ileum mucosa of broilers. Kafkas Üniversitesi Veteriner Fakültesi Dergisi, 23, 571-577.

Zheng, L.Y. \& Zhu, J.F., 2003. Study on antimicrobial activity of chitosan with different molecular weights. Carbohydrate Polymers 54, 527-530.

Zhou, T.X., Chen, Y.J., Yoo, J.S., Huang, Y., Lee, J.H., Jang, H.D., Shin, S.O., Kim, H.J., Cho, J.H. \& Kim, I.H., 2009. Effects of chitooligosaccharide supplementation on performance, blood characteristics, relative organ weight, and meat quality in broiler chickens. Poult. Sci. 88, 593-600. 